\title{
Does size matter? A national analysis of the utility of induction therapy for large thymomas
}

\author{
Douglas Z. Liou ${ }^{1}$, Divya Ramakrishnan ${ }^{1}$, Natalie S. Lui ${ }^{1}$, Joseph B. Shrager ${ }^{1,2}$, Leah M. Backhus ${ }^{1,2}$, \\ Mark F. Berry ${ }^{1,2}$ \\ ${ }^{1}$ Department of Cardiothoracic Surgery, Stanford University, Stanford, CA, USA; ${ }^{2}$ VA Palo Alto Health Care System, Palo Alto, CA, USA \\ Contributions: (I) Conception and design: MF Berry; (II) Administrative support: None; (III) Provision of study materials or patients: MF Berry; (IV) \\ Collection and assembly of data: MF Berry, DZ Liou; (V) Data analysis and interpretation: All authors; (VI) Manuscript writing: All authors; (VII) \\ Final approval of manuscript: All authors. \\ Correspondence to: Mark F. Berry, MD. 300 Pasteur Drive, Falk Cardiovascular Research Institute, Stanford, CA 94305, USA. Email: berry037@stanford.edu.
}

\begin{abstract}
Background: Tumor size of $8 \mathrm{~cm}$ or greater is a risk factor for recurrence after thymoma resection, but the role of induction therapy for large thymomas is not well defined. This study tested the hypothesis that induction therapy for thymomas $8 \mathrm{~cm}$ and larger improves survival.

Methods: The use of induction therapy for patients treated with surgical resection for Masaoka stage IIII thymomas in the National Cancer Database between 2006-2013 was evaluated using logistic regression, Kaplan-Meier analysis, and Cox-proportional hazards methods.

Results: Of the 1,849 patients who met inclusion criteria, $582(31.5 \%)$ had tumors $\geq 8 \mathrm{~cm}$. Five-year survival was worse in patients with tumors $\geq 8 \mathrm{~cm}$ compared to smaller tumors [84.6\% (95\% CI: 81.2-88.1\%) vs. $89.4 \%$ (95\% CI: 87.2-91.7\%), $\mathrm{P}=0.003$ ]. Induction therapy was used in $166(9.0 \%)$ patients overall and was more likely in patients with tumors $\geq 8 \mathrm{~cm}$ [adjusted odds ratio (AOR) 3.257, $\mathrm{P}<0.001$ ]. Induction therapy was not associated with improved survival in the subset of patients with tumors $\geq 8 \mathrm{~cm}$ in either univariate [80.9\% (95\% CI: 72.6-90.1\%) vs. 85.4\% (95\% CI: 81.8-89.3\%), P=0.27] or multivariable analysis [hazard ratio (HR) 1.54, $\mathrm{P}=0.10$ ]. Increasing age (HR 1.56/decade, $\mathrm{P}<0.001$ ) and Masaoka stage III (HR 1.76, $\mathrm{P}=0.04$ ) were associated with worse survival in patients with tumors $\geq 8 \mathrm{~cm}$.

Conclusions: Survival after thymoma resection is worse for tumors $8 \mathrm{~cm}$ or larger compared to smaller tumors and is not improved by induction therapy. Size alone should not be a criterion for using induction therapy prior to thymoma resection.
\end{abstract}

Keywords: Thymoma; induction therapy; survival analysis; mortality

Submitted Nov 08, 2019. Accepted for publication Jan 31, 2020.

doi: $10.21037 /$ jtd.2020.02.63

View this article at: http://dx.doi.org/10.21037/jtd.2020.02.63

\section{Introduction}

Thymomas are uncommon and slow growing tumors that arise from epithelial cells of the thymus gland. The overall incidence in the United States is estimated to be approximately 0.15 cases per 100,000 person-years, which translates to around 400 cases per year for the entire country $(1,2)$. Although rare, thymomas represent the most common mediastinal neoplasm in the adult population, making up approximately $20 \%$ of all mediastinal tumors and $50 \%$ of tumors arising in the anterior mediastinum (3). The incidence increases steadily between ages 40 and 70 years, and peaks in the seventh decade of life $(1,3,4)$. Interestingly, thymomas occur more frequently among blacks and Asians/Pacific Islanders compared to whites or Hispanics, suggesting possible genetic risk factors $(1,2)$. Although typically considered to have an indolent growth pattern, thymomas are nonetheless malignant due to the potential for local invasion, pleural dissemination, and systemic metastasis. As such, surgery is the gold standard 
treatment for this disease, and completeness of resection is consistently shown to be a major prognostic factor (4-10).

The determination of resectable disease is somewhat variable depending on surgical experience and expertise. Factors that generally influence resectability include local invasion of adjacent structures and pleural or pericardial dissemination, which constitute stage III and IVa disease, respectively, according to the Masaoka-Koga classification system. At the time of diagnosis, approximately one-third of patients present with stage III-IVa disease $(6,7,9,10)$. The International Thymic Malignancy Interest Group (ITMIG) dataset published in 2014 consisted of nearly 5,000 thymoma patients, with $30 \%$ reported as stage III-IVa (11). In such cases of locally advanced disease, a multidisciplinary approach has become essential and the use of induction therapy prior to surgery has improved rates of complete resection and overall survival (3,5,6,12-15). Tumor size is another factor that has been independently associated with increased risk of recurrence (16-18) and survival $(8,10,19,20)$. Based on this observation, the use of induction therapy specifically for large thymomas has been suggested $(16,18)$, however data on this topic is lacking. Thus, the purpose of this study was to test the hypothesis that induction therapy prior to surgery for patients with large thymomas improves long-term survival using a large nationwide cancer database.

\section{Methods}

\section{Data source}

A retrospective analysis was performed utilizing data from the National Cancer Database (NCDB). The NCDB is a joint venture between the American College of Surgeons Commission on Cancer (CoC) and the American Cancer Society, and is estimated to capture $70 \%$ of all newly diagnosed cancers in the United States. The database collects data from more than 1,500 CoC-approved facilities in North America, and currently contains more than 30 million records.

With respect to staging for thymomas, the NCDB does not specifically report tumor stage according to the Masaoka-Koga classification system. Thus, staging data was inferred from available variables including regional lymph node status and the Collaborative Staging Extension codes, which describe the extent of tumor involvement based on pathology data. Patients with distant metastases or lymph node involvement were considered to have stage IV disease and therefore excluded from this analysis of patients with stage I-III disease. The stages of the remaining patients were then determined based on primary tumor extension using a previously described method $(21,22)$. Patients whose local extension was "confined to gland of origin" or "localized not otherwise specified" were considered to have Masaoka stages I-IIa; these two stages were grouped together because the staging schema used by the NCDB does not report on microcapsular invasion. Tumors coded as "invasive to adjacent connective tissue" were considered Masaoka stage IIb, and tumors involving "adjacent organs and structures" were considered Masaoka stage III.

\section{Patient selection}

Patients with Masaoka stage I-III thymomas diagnosed between 2006 to 2013 who underwent surgical resection were included in the analysis. This study period was chosen on the basis of the availability of data in the NCDB at the time of analysis. Only patients with complete data with respect to tumor size, local tumor extension, known use and sequence of treatment (surgery, chemotherapy, radiation), and survival were included in the overall analysis. Tumor size measurements in the NCDB are based on radiographic studies for patients who underwent induction therapy and pathology specimens for patients who had primary surgery. Patients with missing data for any of the variables included in the logistic regression and proportional hazards models were not included in these models. Patients with previous malignancies and incomplete follow-up data were excluded.

\section{Statistical analysis}

Patients were stratified into two groups according to induction therapy status. Patients who received some form of induction therapy were compared to those who did not using Wilcoxon rank-sum test for continuous variables, Pearson's chi-square test for discrete variables, and Fisher's exact test for those discrete variables with fewer than 5 outcomes. Independent predictors of the use of induction therapy prior to surgical resection were estimated using a multivariable logistic regression model that included age, sex, race, insurance status, Charlson comorbidity index, median census tract education level, median census tract income level, treatment facility type, distance traveled to treating facility, tumor invasion, and tumor size.

The impact of tumor size and the use of induction therapy on survival was assessed with Kaplan-Meier analysis 
Table 1 Tumor characteristics and induction therapy status

\begin{tabular}{|c|c|c|c|c|}
\hline $\begin{array}{l}\text { Tumor characteristics and induction } \\
\text { therapy status }\end{array}$ & Total $(n=1,849)$ & $\begin{array}{l}\text { No induction therapy } \\
\qquad(\mathrm{n}=1,683)\end{array}$ & $\begin{array}{l}\text { Induction therapy } \\
\qquad(n=166)\end{array}$ & $P$ \\
\hline Tumor size $(\mathrm{cm})$, median [IQR] & $6.2[4.4,8.7]$ & $6.0[4.2,8.5]$ & $9.0[6.9,11.2]$ & 0.015 \\
\hline$\geq 8$ & $582(31.5)$ & $480(28.5)$ & $102(61.4)$ & \\
\hline Masaoka stage, n (\%) & & & & $<0.001$ \\
\hline I-Ila & 877 (47.4) & $842(50.0)$ & $35(21.1)$ & \\
\hline $\mathrm{Ilb}$ & $446(24.1)$ & $420(25.0)$ & $26(15.7)$ & \\
\hline Induction chemotherapy, n (\%) & $162(8.8)$ & $0(0.0)$ & $162(97.6)$ & $<0.001$ \\
\hline Induction radiation, n (\%) & $25(1.4)$ & $0(0.0)$ & $25(15.1)$ & $<0.001$ \\
\hline
\end{tabular}

and the log-rank test. The independent impact of tumor size and induction therapy use was further evaluated using a Cox proportional hazards model. Variables chosen for inclusion in the Cox model were patient (age, sex, comorbidities) and tumor characteristics (Masaoka stage, tumor size, margin status) previously shown to be associated with survival, along with the study variable of interest (induction therapy). This Cox model was adjusted for clustering by hospital by including the specific facility in the model as a random effect. In order to test the primary hypothesis that induction therapy prior to surgery for patients with large thymomas improves long-term survival, the above survival analysis was repeated on the subgroup of patients with thymomas $8 \mathrm{~cm}$ and larger. This size cutoff was chosen based on previous literature indicating that this tumor size is an independent predictor of recurrence and mortality after surgery (18).

A propensity matched analysis was also performed to further address issues of potential confounding and bias in the use of induction therapy. Propensity scores were defined as the probability of induction therapy versus no induction therapy conditional on other measured covariates, which included patient age, sex, Charlson comorbidity index, tumor size, Masaoka, stage, histology, insurance status, and treatment facility type. Patients were matched based on propensity scores using a 1:1 nearest neighbor algorithm. Propensity measurements were estimated using a standard logistic regression model without replacement. Following propensity matching, balance was assessed between groups based on standardized differences. Survival between groups was assessed with the Kaplan-Meier method and log-rank test.

Continuous data are presented as median with interquartile range, and categorical variables are presented as frequency and percentage. A $\mathrm{P}$ value of $<0.05$ was considered statistically significant. All analyses were performed using $\mathrm{R}$ version 3.2.2 (R Foundation for Statistical Computing, Vienna, Austria). This study was approved by the Stanford Institutional Review Board.

\section{Results}

During the study period, 1,849 patients with Masaoka stage I-III thymoma underwent surgical resection, 582 (31.5\%) of whom had tumors $\geq 8 \mathrm{~cm}$ in size. Among the study cohort, $166(9.0 \%)$ patients received induction therapy prior to surgery and 1,683 (91.0\%) did not. Induction chemotherapy was given in $162(97.6 \%)$ patients and induction radiation in $25(15.1 \%)$ patients. Baseline characteristics of the entire study cohort as well as the cohort stratified by induction therapy use are shown in Table 1, and additional baseline characteristics are available in Table 2. Patients who received induction therapy were slightly younger compared to 
Table 2 Baseline characteristics for the entire study cohort and stratified by induction therapy status

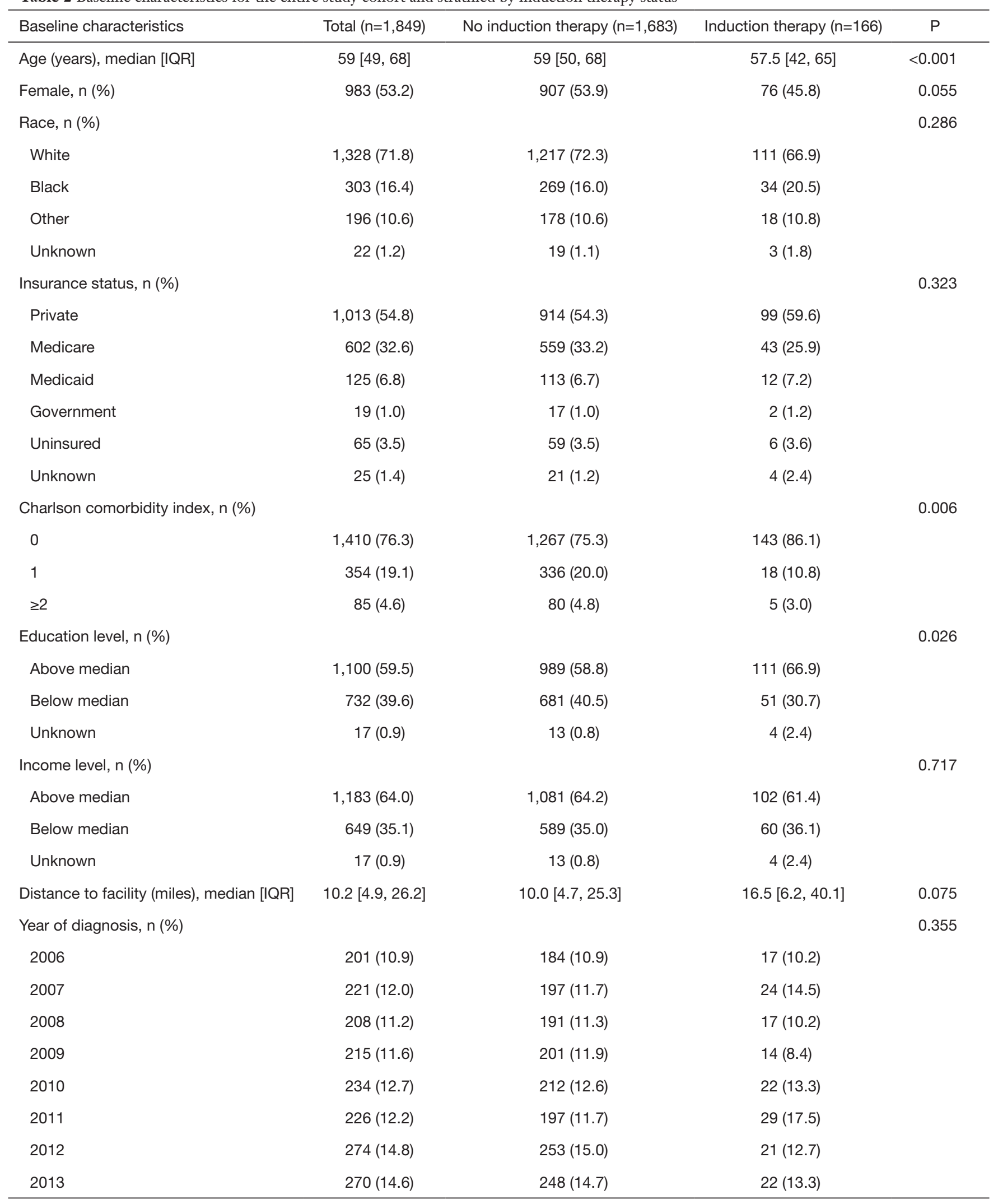

Table 2 (continued) 
Table 2 (continued)

\begin{tabular}{lccc}
\hline Baseline characteristics & Total $(\mathrm{n}=1,849)$ & No induction therapy $(\mathrm{n}=1,683)$ & Induction therapy $(\mathrm{n}=166)$ \\
\hline Histology, $\mathrm{n}(\%)$ & & & 0.076 \\
Type A & $178(9.6)$ & $168(10.0)$ & $10(6.0)$ \\
Type AB & $422(22.8)$ & $390(23.2)$ & $32(19.3)$ \\
Type B1 & $271(14.7)$ & $242(14.4)$ & $29(17.5)$ \\
Type B2 & $318(17.2)$ & $296(17.6)$ & $22(13.3)$ \\
Type B3 & $287(15.5)$ & $34(20.5)$ \\
Not specified & $373(20.2)$ & $34(15.0)$ & $39(23.5)$ \\
Facility type, $n$ (\%) & & $710(42.2)$ & $82(49.4)$ \\
Research/academic & $792(42.8)$ & $599(35.6)$ & $35(21.1)$ \\
Comprehensive community & $634(34.3)$ & $81(4.8)$ & $4(2.4)$ \\
Community & $85(4.6)$ & $293(17.4)$ & $45(27.1)$ \\
Unknown & $338(18.3)$ & & 0.02 \\
\hline
\end{tabular}

those who did not (57.5 vs. 59 years, $\mathrm{P}<0.001)$. Induction therapy patients also had a higher incidence of Charlson comorbidity index of $0(86.1 \% v s .75 .3 \%, \mathrm{P}=0.006)$ and were more likely to have an education level above the census tract median. There were no differences in gender, race, insurance status, income level, distance traveled to treating facility, year of diagnosis, or histologic subtype between the two groups. Patients who received induction therapy had a median tumor size of $9.0 \mathrm{~cm}$ compared to $6.0 \mathrm{~cm}$ for those who did not $(\mathrm{P}=0.015)$. Similarly, $61.4 \%$ of induction therapy patients had tumors $\geq 8 \mathrm{~cm}$ in size compared to only $28.5 \%$ of patients who received no induction therapy $(\mathrm{P}<0.001)$. Induction therapy patients were treated more often at a research or academic facility and had a greater incidence of Masaoka stage III disease (63.3\% vs. $25.0 \%$, $\mathrm{P}<0.001)$.

Predictors of induction therapy based on multivariable analysis are presented in Table 3. Education level above the census tract median [adjusted odds ratio (AOR) 2.106, $\mathrm{P}=0.006]$, treatment at an academic or research facility (AOR 1.880, $\mathrm{P}=0.006$ ), and increasing distance traveled to the treating facility ( $\mathrm{AOR} 1.064$ per 50 miles, $\mathrm{P}=0.023$ ) were all independently associated with induction therapy. In contrast, Charlson comorbidity index of 1 was associated with a lower odds ratio of undergoing induction therapy (AOR 0.440, $\mathrm{P}=0.019$ ). Having either an invasive tumor (Masaoka stage IIb-III) or large tumor $(\geq 8 \mathrm{~cm})$ conferred greater than three-fold odds of receiving induction therapy prior to surgery (AOR 3.488 and 3.257, respectively, both $\mathrm{P}<0.001)$.

Induction therapy patients underwent definitive surgical resection several months later than patients with no induction therapy (137 vs. 0 days, $\mathrm{P}<0.001$ ), and had slightly longer hospital length of stay ( 5 vs. 4 days, $\mathrm{P}<0.001)$ (Table 4). There was no difference in margin status between the two groups, however patients who did not receive induction therapy were more likely to undergo adjuvant radiation postoperatively ( $43.6 \%$ vs. $33.7 \%, \mathrm{P}=0.018$ ). Unplanned readmissions and postoperative mortality were not significantly different. A subgroup analysis of perioperative outcomes for patients with tumor size $\geq 8 \mathrm{~cm}$ yielded similar results regarding time to definitive surgery, postoperative length of stay, and adjuvant radiation therapy (Table 4). Additionally, this subset of induction therapy patients had a higher 90-day mortality rate compared to patients with large thymomas who did not receive induction therapy (3.9\% vs. $0.8 \%, \mathrm{P}=0.036$ ).

Five-year survival was worse for patients with tumors $\geq 8 \mathrm{~cm}$ compared to patients with smaller tumors [84.6\% (95\% CI: $81.2-88.1 \%$ ) vs. $89.4 \%$ (95\% CI: $87.2-91.7 \%$ ), $\mathrm{P}=0.003$ ] (Figure 1). Based on Kaplan-Meier survival analysis, there was no difference in overall survival between patients who received induction therapy and those who did not, for both the entire study cohort (Figure $2 A$ ) and the subset of patients with tumors $\geq 8 \mathrm{~cm}$ in size (Figure $2 B$ ). Cox proportional hazards model identified increasing age 
Table 3 Multivariable predictors of induction therapy

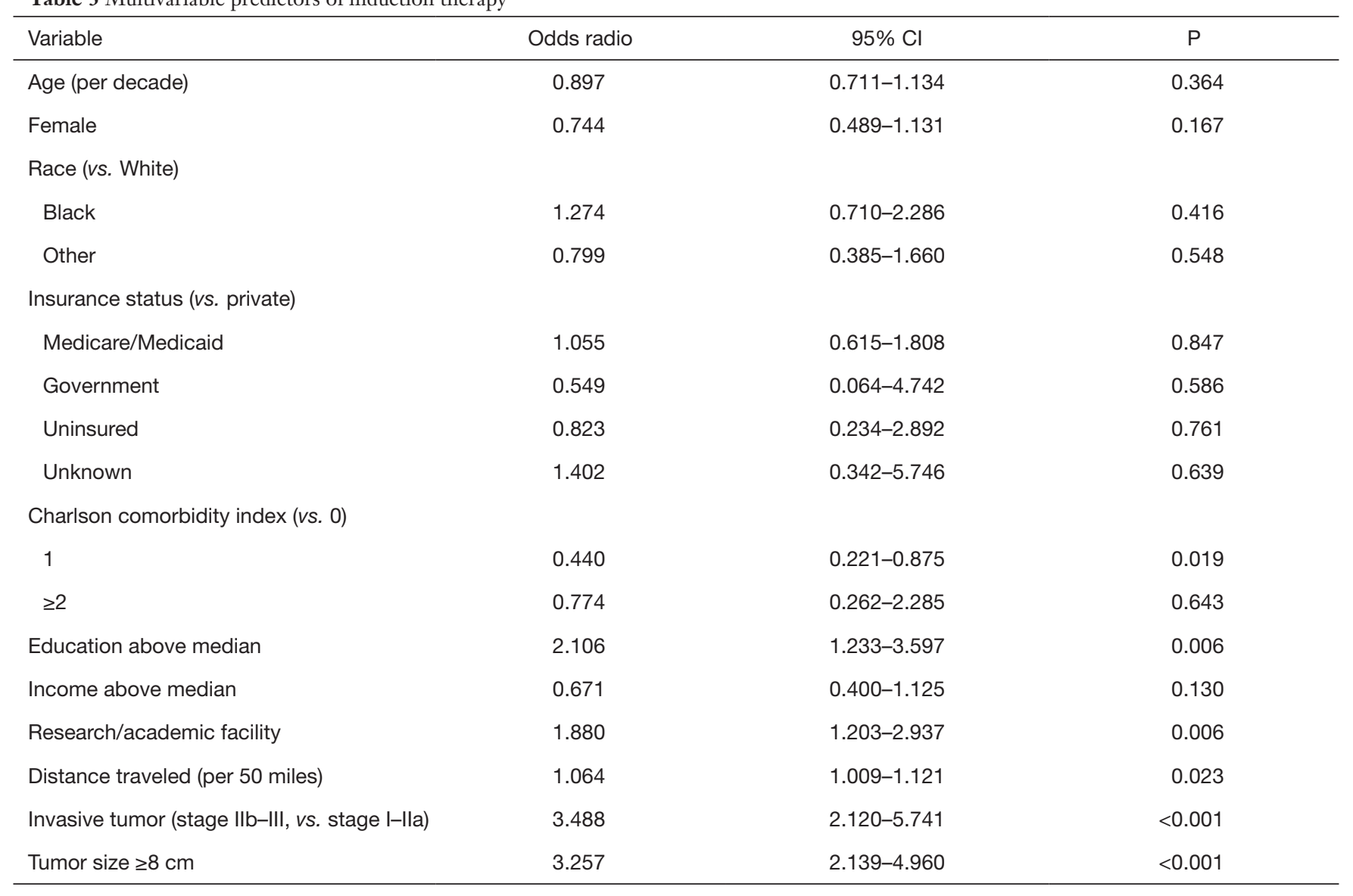

[hazard ratio (HR) 1.68 per decade, $\mathrm{P}<0.001$ ], Masaoka stage III (HR 1.93, $\mathrm{P}<0.001$ ) and tumor size $\geq 8 \mathrm{~cm}$ (HR 1.47, $\mathrm{P}=0.01$ ) as factors associated with worse survival (Table 5). For the subset of patients with tumors $\geq 8 \mathrm{~cm}$, increasing age (HR 1.56 per decade, $\mathrm{P}<0.001$ ) and Masaoka stage III (HR $1.76, \mathrm{P}=0.04)$ were similarly associated with worse survival (Table 5). However, the use of induction therapy was not significantly associated with survival for the entire study cohort (HR 1.32, $\mathrm{P}=0.25)$ nor in patients with tumor size $\geq$ $8 \mathrm{~cm}$ (HR 1.54, $\mathrm{P}=0.10)$.

The propensity matched analysis found results consistent with the primary analysis. Specifically, the analysis demonstrated that the propensity-matched groups were well balanced, and that differences in perioperative outcomes were consistent with those of the initial analysis for the entire study cohort (Table 6). Additionally, there was no statistically significant difference in survival between the two propensity-matched groups (Figure 2C).

\section{Discussion}

Thymomas are by and large considered a surgical disease. Irrespective of stage, the best chance for cure from a treatment modality standpoint is complete surgical resection. Accordingly, in locally advanced tumors the treatment strategy is centered on preoperative therapy that ultimately leads to a chance for complete resection. There is literature demonstrating improved rates of complete resection and overall survival in patients with Masaoka stage III and IVa thymomas who undergo induction therapy prior to surgery $(5,15,23-26)$, although data is limited to retrospective studies or prospective trials with small sample size due to the rarity of this disease. Nonetheless, clinical practice guidelines published by the 
Table 4 Unadjusted perioperative outcomes for the entire cohort and for the subset of patients with large tumors

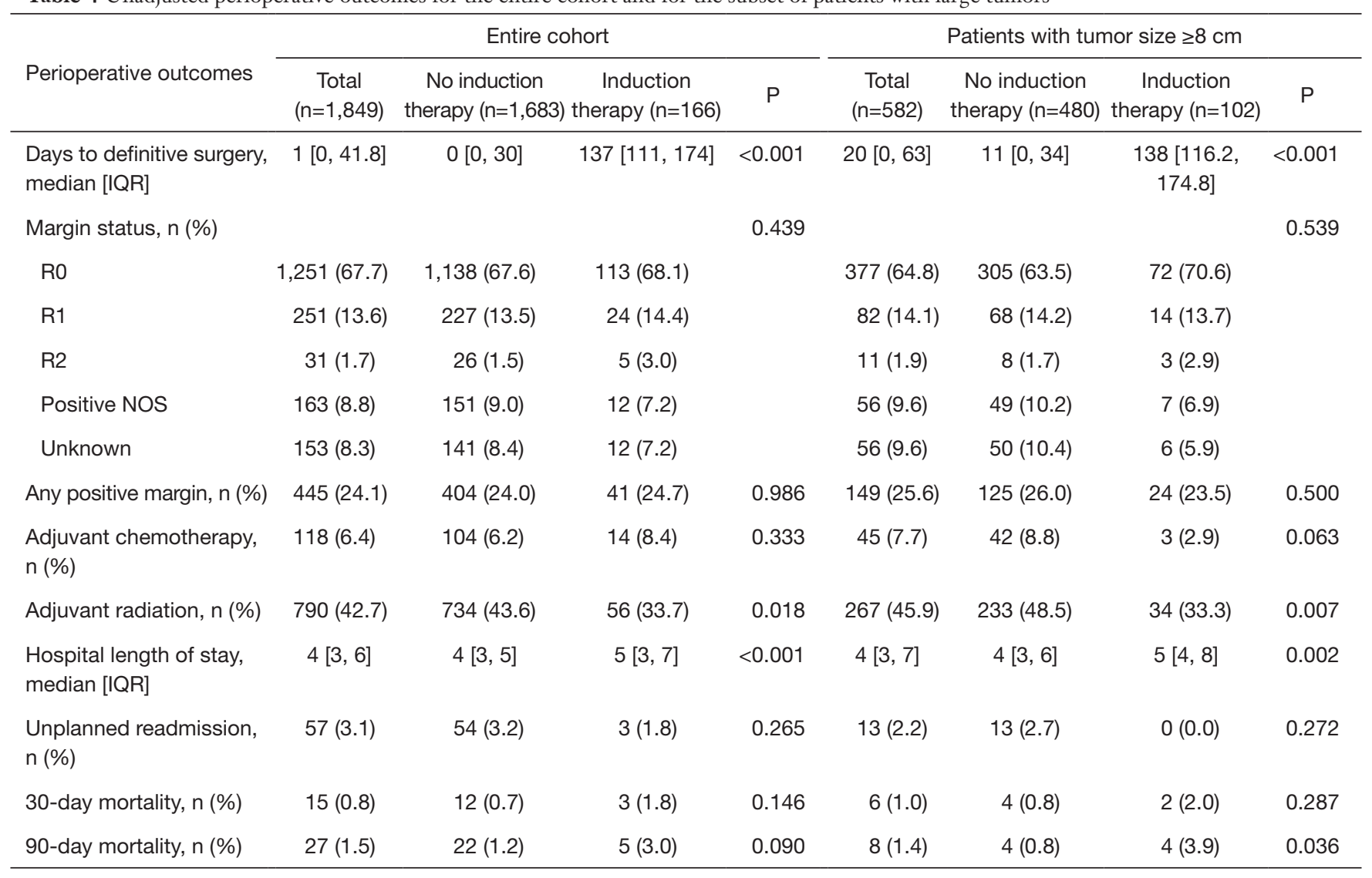

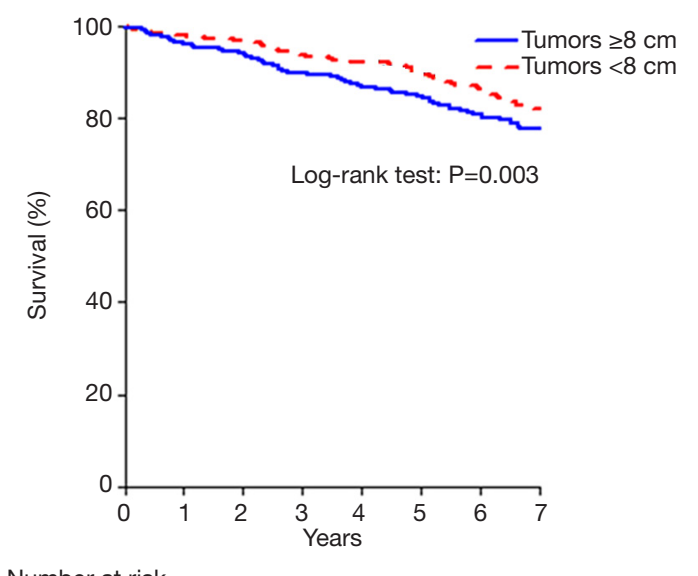

Number at risk

Tumors $\geq 8 \mathrm{~cm}$-582 $526467 \quad 367 \quad 293 \quad 214 \quad 155 \quad 103$

Tumors $<8 \mathrm{~cm}-1,1551,059923 \quad 709537402 \quad 267 \quad 169$

Figure 1 Survival after resection of Masaoka stage I-III thymoma stratified by tumor size.
National Comprehensive Cancer Network (NCCN) $(4,27)$ as well as other international groups $(28,29)$ advocate a multidisciplinary approach utilizing induction therapy followed by reassessment for surgery in all patients with advanced disease. For large tumors that are not necessarily invasive, however, it is unknown if induction therapy has any benefit on long-term survival. Intuitively, this approach would seem to be advantageous since large thymomas have been associated with worse outcomes $(8,10,16-20)$. Analysis from the current study indicates that induction therapy was more likely to be used for large tumors, but this did not improve survival for tumors $8 \mathrm{~cm}$ or larger after adjusting for confounding variables such as tumor stage. Therefore, using tumor size alone as a criterion for induction therapy is not supported by these results.

Numerous studies on thymoma have consistently shown an association between larger tumor size and higher 
A

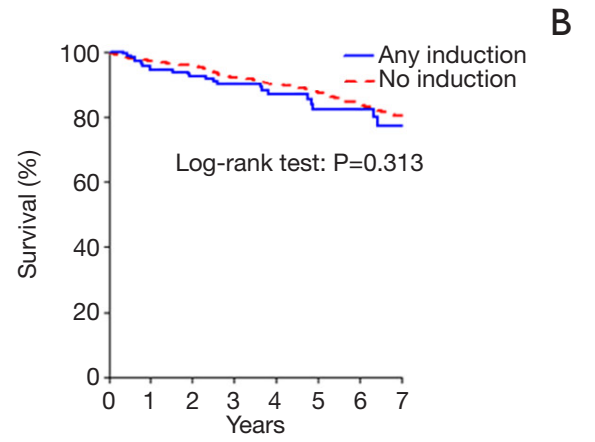

Number at risk

Any induction - 166 $148 \begin{array}{lllllll}134 & 108 & 78 & 50 & 35 & 24\end{array}$

No induction -1,683 1,533 1,339 1,036 $811 \quad 612 \quad 421 \quad 272$

B

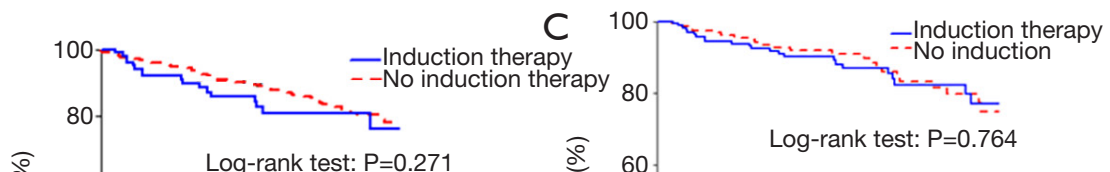

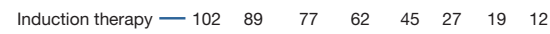

No induction therapy — $\begin{array}{llllllll}480 & 437 & 390 & 305 & 248 & 187 & 136 & 91\end{array}$

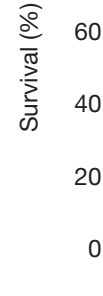

$\begin{array}{llllllll}\text { Induction therapy - } 166 & 148 & 134 & 108 & 78 & 50 & 35 & 24\end{array}$

No induction - $\begin{array}{llllllll}166 & 153 & 134 & 110 & 82 & 62 & 41 & 25\end{array}$

Figure 2 Survival stratified by induction therapy versus no induction therapy for (A) the entire cohort, (B) patients with tumor size $\geq 8 \mathrm{~cm}$, and (C) propensity-matched subgroups.

Table 5 Cox proportional hazards model for the entire cohort and for the subset of patients with large tumors

\begin{tabular}{|c|c|c|c|c|c|c|}
\hline \multirow{2}{*}{ Variable } & \multicolumn{3}{|c|}{ Entire cohort } & \multicolumn{3}{|c|}{ Patients with tumors size $\geq 8 \mathrm{~cm}$} \\
\hline & Hazard radio & $95 \% \mathrm{Cl}$ & $\mathrm{P}$ & Hazard radio & $95 \% \mathrm{Cl}$ & $\mathrm{P}$ \\
\hline Age (per decade) & 1.68 & $1.49-1.90$ & $<0.001$ & 1.56 & $1.31-1.86$ & $<0.001$ \\
\hline Female & 1.10 & $0.82-1.48$ & 0.50 & 1.26 & $0.81-1.95$ & 0.30 \\
\hline \multicolumn{7}{|c|}{ Charlson comorbidity index (reference: 0) } \\
\hline 1 & 1.44 & $1.03-2.02$ & 0.03 & 1.09 & $0.62-1.92$ & 0.80 \\
\hline$\geq 2$ & 1.46 & $0.78-2.75$ & 0.20 & 1.79 & $0.70-4.57$ & 0.20 \\
\hline \multicolumn{7}{|c|}{ Masaoka stage (reference: stage I-Ila) } \\
\hline $\mathrm{Ilb}$ & 1.06 & $0.72-1.58$ & 0.80 & 0.85 & $0.43-1.68$ & 0.60 \\
\hline III & 1.93 & $1.36-2.75$ & $<0.001$ & 1.76 & $1.04-2.99$ & 0.04 \\
\hline Any induction therapy & 1.32 & $0.82-2.12$ & 0.25 & 1.54 & $0.91-2.64$ & 0.10 \\
\hline Positive margin & 1.09 & $0.79-1.50$ & 0.60 & 1.24 & $0.78-1.98$ & 0.40 \\
\hline Tumor size $\geq 8 \mathrm{~cm}$ & 1.47 & $1.09-1.98$ & 0.01 & $\mathrm{n} / \mathrm{a}$ & $n / a$ & $\mathrm{n} / \mathrm{a}$ \\
\hline
\end{tabular}

Table 6 Baseline characteristics and perioperative outcomes for a propensity-matched subset stratified by induction therapy status

\begin{tabular}{lcccc}
\hline Baseline characteristics & $\begin{array}{c}\text { No induction therapy } \\
(\mathrm{n}=166)\end{array}$ & $\begin{array}{c}\text { Induction therapy } \\
(\mathrm{n}=166)\end{array}$ & $\mathrm{P}$ & $\begin{array}{c}\text { Standardized } \\
\text { differences }\end{array}$ \\
\hline Age (years), median [IQR] & $55[46,64]$ & $57.5[42,65]$ & 0.902 & 0.036 \\
Female, $\mathrm{n}(\%)$ & $76(45.8)$ & $76(45.8)$ & 0.999 & 0 \\
Charlson comorbidity index, $\mathrm{n}(\%)$ & & & 0.558 & 0.127 \\
0 & $147(88.6)$ & $143(86.1)$ & & \\
1 & $17(10.2)$ & $18(10.8)$ & & \\
$\geq 2$ & $2(1.2)$ & $5(3.0)$ & \\
\hline
\end{tabular}

Table 6 (continued) 
Table 6 (continued)

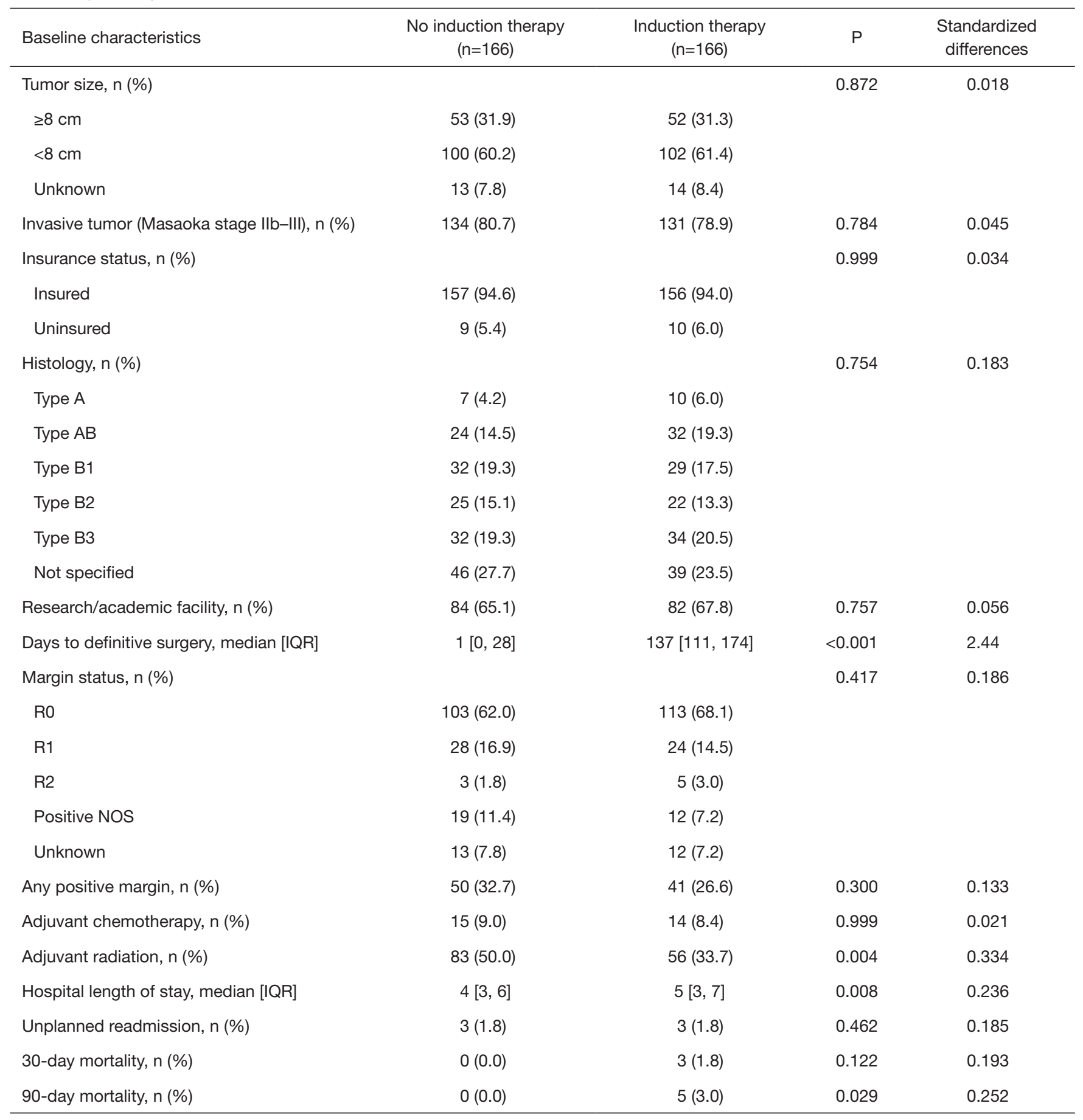


recurrence rates along with lower survival, and this study similarly found that tumor size $8 \mathrm{~cm}$ and greater was an independent predictor of worse survival. This finding may be partially due to the correlation between tumor size and invasiveness. Our data shows that the induction therapy group had greater than $60 \%$ of patients with tumor size $\geq 8 \mathrm{~cm}$ and stage III disease, compared to roughly $25 \%$ in each category for patients who did not receive induction therapy. A study on predictors of thymoma invasiveness based on computed tomography (CT) characteristics found that pre-chemotherapy radiologic tumor size of $7 \mathrm{~cm}$ or greater was associated with a higher likelihood of stage III and IV disease (30). Although many studies adjust for tumor size and stage when evaluating outcomes, both features are consistently linked to worse recurrence rates and survival after resection. Despite the worse outcomes observed with larger tumors, induction therapy use does not appear to improve those outcomes.

Much of the literature examining tumor size note that a threshold of around $8 \mathrm{~cm}$ or larger is associated with poor outcomes $(8,10,16,18,20,31)$. These previous studies were the basis of selecting $8 \mathrm{~cm}$ as the size cutoff for our analysis. One retrospective study on 154 patients with thymic epithelial tumors reported a much lower size threshold of $4 \mathrm{~cm}$ as the inflection point for recurrence-free survival (32). However, approximately $20 \%$ of patients in that study had pathology showing either thymic carcinoma or neuroendocrine tumor, both of which are generally considered more aggressive than thymomas and thus do not represent the same patient population. Since thymoma size is a significant prognostic factor and can be reliably measured preoperatively with imaging studies, some authors suggest size should be a contributing factor when considering induction therapy $(16,18)$. To the contrary, however, our findings indicate induction therapy does not provide any long-term survival benefit when administered on the basis of tumor size alone.

It is possible that there may be situations where induction therapy provides survival benefit, specifically if induction facilitates resection in a locally advanced tumor. As previously noted, the purpose of induction therapy is to increase the likelihood of complete resection, which is the mainstay of treatment for thymomas and the best chance of cure. Thymomas that invade adjacent structures can be technically more difficult to remove and have a higher chance of close margins or incomplete resection, particularly in cases where major vascular structures are involved (33). A large thymoma that is not attached to other structures, however, may not pose the same technical challenges as an invasive tumor does, especially if an open surgical approach is utilized. Thus, the benefit gained from preoperative treatment aimed at shrinking the tumor may not be as impactful with respect to completeness of resection for large thymomas that are noninvasive. There are lines of data that seem to support this theory. A study utilizing CT scans to predict surgical resectability found that preoperative tumor size was larger in patients with incomplete resection compared to those who had a complete resection on univariate analysis (34). However, adjusted analysis showed that only tumor abutment of adjacent vessels and pleural nodularity were predicative of incomplete resection. Another study found that stage III disease involving the great vessels had 30\% lower rate of complete resection and worse survival compared to stage III disease with no great vessel involvement (33), which similarly highlights the important associations between tumor invasiveness, resectability, and long-term outcomes. One significant limitation to the current study is that the indication for induction therapy is not recorded, therefore we cannot account for the potential bias of induction therapy being used more often for tumors that were judged pre-therapy to involve local structures.

Given these previous studies and our current results, we do advocate for multidisciplinary evaluation prior to treating a large thymoma. In particular, we would encourage experienced thoracic surgeons to be involved in the decision process on whether induction therapy should be used. Evaluating the local extent and invasiveness of large thymomas based on pre-treatment imaging can be difficult because such tumors inevitably abut at least the sternum, chest wall, pericardium, and lung due to their location in the mediastinum. Although our study does not support preoperative treatment based on size alone, we do feel strongly that a thoracic surgeon's input as to whether a tumor is likely to be locally invasive should be a major determinant when deciding on induction therapy.

The induction therapy group in our study had a higher incidence of invasive disease and more than double the rate of stage III tumors. Despite this, there were equal rates of R0 resection, nearly $75 \%$, between the two groups. The implication is that induction therapy improved resectability for the higher stage group, which is consistent with results from previously published data. Similar survival between the two groups is likely related to the equivalent rates of complete resection. Another interesting finding from our study is related to rates of adjuvant radiation 
therapy, which was approximately $30 \%$ and $45 \%$ higher in the groups that did not receive induction therapy for the entire cohort and the subset of patients with thymomas $\geq 8 \mathrm{~cm}$, respectively. However, higher rates of adjuvant radiation therapy did not translate to improved survival in those groups. This finding is not surprising given that the benefit of this treatment modality is primarily for non-localized thymomas (21), but not in incidences where complete resection was achieved (35). In the current study, the groups that did not receive induction therapy had higher rates of adjuvant radiation but lower incidences of non-localized disease, therefore a significant survival benefit would not be expected in those groups.

In addition to the limitation noted above regarding the inability to determine indications for induction therapy, there are several other notable limitations that should be highlighted. As with all retrospective studies, causality cannot be established between variables but only associations. The extent of our analysis is confined to the data elements present in the NCDB. As such, granular data with respect to surgical technique, surgeon specialty, and short-term post-treatment outcomes is not available. These variables potentially relate to the ability to achieve complete surgical resection and without violation of the tumor capsule, both of which impact survival. Masaoka stage is not explicitly listed in the NCDB, therefore it is inferred based on pathologic data pertaining to local tumor extension. Similarly, the authors elected to use Masaoka stage instead of the recently adopted $8^{\text {th }}$ edition TNM staging system in this analysis given that Masaoka staging was the most commonly used system during the study period. Specific chemotherapy agents and regimens used are not recorded. Complications are not listed in the NCDB, therefore the frequency and severity of adverse events can only be inferred based on readmissions and perioperative mortality. Furthermore, the NCDB only captures same-hospital readmissions, thus the true incidence of postoperative readmissions is likely underestimated. Due to the retrospective nature of the study, an intent-to-treat analysis could not be performed.

An additional important limitation is related to the duration of follow-up in this study. Even in locally advanced or metastatic thymomas the disease tends to progress relatively slowly, thus survival is much better compared to other cancers at similarly advanced stages. It is possible that the length of follow-up in our study, which was at most seven years, was not long enough to allow a benefit of induction therapy to become apparent. Although our study did not suggest any potential signal of benefit for large thymomas, a follow-up to the current study should be done when more patients are available and a longer duration after the initial surgery can be evaluated. Finally, another important variable that is not present in the NCDB is recurrence, therefore this could not be analyzed in the setting of induction therapy. As noted above, recurrencefree survival is closely related to tumor size, stage, and completeness of resection. Recurrence does tend to occur within a few years of treatment, but patients with recurrent thymoma often still have prolonged survival. Unfortunately, the current study does not provide data on whether induction therapy impacts recurrence rates.

\section{Conclusions}

Long-term survival after surgical resection of thymomas 8 $\mathrm{cm}$ or greater in size was worse compared to that of smaller tumors. In addition to tumor size, older age and Masaoka stage III disease predicted worse survival for all patients with thymomas who underwent surgical resection. The use of induction therapy in large thymomas was not associated with improved survival. Size alone should not be a criterion when determining if induction therapy should be used.

\section{Acknowledgments}

The data used in this study are derived from a de-identified National Cancer Database file. The American College of Surgeons has executed a Business Associate Agreement that includes a data use agreement with each of its Commission on Cancer accredited hospitals. The American College of Surgeons and the Commission on Cancer have not verified and are not responsible for the analytic or statistical methodology employed, or the conclusions drawn from these data by the investigators.

Funding: None.

\section{Footnote}

Conflicts of Interest: All authors have completed the ICMJE uniform disclosure form (available at http://dx.doi. org/10.21037/jtd.2020.02.63). NSL serves as an unpaid editorial board member of Fournal of Thoracic Disease from Sep 2019 to Aug 2021. MFB serves as an unpaid editorial board member of Journal of Thoracic Disease from Sep 2018 to Aug 2020. The other authors have no conflicts of interest 
to declare..

Ethical Statement: The authors are accountable for all aspects of the work in ensuring that questions related to the accuracy or integrity of any part of the work are appropriately investigated and resolved. This study was approved by the Stanford Institutional Review Board.

Open Access Statement: This is an Open Access article distributed in accordance with the Creative Commons Attribution-NonCommercial-NoDerivs 4.0 International License (CC BY-NC-ND 4.0), which permits the noncommercial replication and distribution of the article with the strict proviso that no changes or edits are made and the original work is properly cited (including links to both the formal publication through the relevant DOI and the license). See: https://creativecommons.org/licenses/by-nc-nd/4.0/.

\section{References}

1. Engels EA. Epidemiology of thymoma and associated malignancies. J Thorac Oncol 2010;5:S260-5.

2. Engels EA, Pfeiffer RM. Malignant thymoma in the United States: demographic patterns in incidence and associations with subsequent malignancies. Int $\mathrm{J}$ Cancer 2003;105:546-51.

3. Wright CD. Management of thymomas. Crit Rev Oncol Hematol 2008;65:109-20.

4. Ettinger DS, Riely GJ, Akerley W, et al. Thymomas and thymic carcinomas: Clinical Practice Guidelines in Oncology. J Natl Compr Canc Netw 2013;11:562-76.

5. Cardillo G, Carleo F, Giunti R, et al. Predictors of survival in patients with locally advanced thymoma and thymic carcinoma (Masaoka stages III and IVa). Eur J Cardiothorac Surg 2010;37:819-23.

6. Detterbeck FC, Parsons AM. Thymic tumors. Ann Thorac Surg 2004;77:1860-9.

7. Kondo K, Monden Y. Therapy for thymic epithelial tumors: a clinical study of 1,320 patients from Japan. Ann Thorac Surg 2003;76:878-84; discussion 884-5.

8. Nakagawa K, Asamura H, Matsuno Y, et al. Thymoma: a clinicopathologic study based on the new World Health Organization classification. J Thorac Cardiovasc Surg 2003;126:1134-40.

9. Regnard JF, Magdeleinat P, Dromer C, et al. Prognostic factors and long-term results after thymoma resection: a series of 307 patients. J Thorac Cardiovasc Surg 1996;112:376-84.
10. Blumberg D, Port JL, Weksler B, et al. Thymoma: a multivariate analysis of factors predicting survival. Ann Thorac Surg 1995;60:908-13; discussion 914.

11. Huang J, Ahmad U, Antonicelli A, et al. Development of the international thymic malignancy interest group international database: an unprecedented resource for the study of a rare group of tumors. J Thorac Oncol 2014;9:1573-8.

12. Ahmad U, Huang J. Induction Therapy for Thymoma. Thorac Surg Clin 2016;26:325-32.

13. Spaggiari L, Casiraghi M, Guarize J. Multidisciplinary treatment of malignant thymoma. Curr Opin Oncol 2012;24:117-22.

14. Rajan A, Giaccone G. Chemotherapy for thymic tumors: induction, consolidation, palliation. Thorac Surg Clin 2011;21:107-14, viii.

15. Bretti S, Berruti A, Loddo C, et al. Multimodal management of stages III-IVa malignant thymoma. Lung Cancer 2004;44:69-77.

16. Safieddine N, Liu G, Cuningham K, et al. Prognostic factors for cure, recurrence and long-term survival after surgical resection of thymoma. J Thorac Oncol 2014;9:1018-22.

17. Ruffini E, Detterbeck F, Van Raemdonck D, et al. Tumours of the thymus: a cohort study of prognostic factors from the European Society of Thoracic Surgeons database. Eur J Cardiothorac Surg 2014;46:361-8.

18. Wright CD, Wain JC, Wong DR, et al. Predictors of recurrence in thymic tumors: importance of invasion, World Health Organization histology, and size. J Thorac Cardiovasc Surg 2005;130:1413-21.

19. Roden AC, Yi ES, Jenkins SM, et al. Modified Masaoka stage and size are independent prognostic predictors in thymoma and modified Masaoka stage is superior to histopathologic classifications. J Thorac Oncol 2015;10:691-700.

20. Harnath T, Marx A, Ströbel P, et al. Thymoma-a clinico-pathological long-term study with emphasis on histology and adjuvant radiotherapy dose. J Thorac Oncol 2012;7:1867-71.

21. Lim YJ, Kim HJ, Wu HG. Role of Postoperative Radiotherapy in Nonlocalized Thymoma: PropensityMatched Analysis of Surveillance, Epidemiology, and End Results Database. J Thorac Oncol 2015;10:1357-63.

22. Kim E, Thomas CR Jr. Conditional survival of malignant thymoma using national population-based surveillance, epidemiology, and end results (SEER) registry (1973-2011). J Thorac Oncol 2015;10:701-7. 
23. Wei Y, Gu Z, Shen Y, et al. Preoperative induction therapy for locally advanced thymic tumors: a retrospective analysis using the ChART database. J Thorac Dis 2016;8:665-72.

24. Hamaji M, Ali SO, Burt BM. A meta-analysis of induction therapy for advanced thymic epithelial tumors. Ann Thorac Surg 2015;99:1848-56.

25. Korst RJ, Bezjak A, Blackmon S, et al. Neoadjuvant chemoradiotherapy for locally advanced thymic tumors: a phase II, multi-institutional clinical trial. J Thorac Cardiovasc Surg 2014;147:36-44, 46.e1.

26. Kim ES, Putnam JB, Komaki R, et al. Phase II study of a multidisciplinary approach with induction chemotherapy, followed by surgical resection, radiation therapy, and consolidation chemotherapy for unresectable malignant thymomas: final report. Lung Cancer 2004;44:369-79.

27. National Comprehensive Cancer Network. Thymomas and thymic carcinomas (Version 1.2017). Available online: https://www.nccn.org/professionals/physician_gls/pdf/ thymic.pdf

28. Girard N, Ruffini E, Marx A, et al. Thymic epithelial tumours: ESMO Clinical Practice Guidelines for diagnosis, treatment and follow-up. Ann Oncol 2015;26 Suppl 5:v40-55.

Cite this article as: Liou DZ, Ramakrishnan D, Lui NS, Shrager JB, Backhus LM, Berry MF. Does size matter? A national analysis of the utility of induction therapy for large thymomas. J Thorac Dis 2020;12(4):1329-1341. doi: 10.21037/ jtd.2020.02.63
29. Falkson CB, Bezjak A, Darling G, et al. The management of thymoma: a systematic review and practice guideline. J Thorac Oncol 2009;4:911-9.

30. Marom EM, Milito MA, Moran CA, et al. Computed tomography findings predicting invasiveness of thymoma. J Thorac Oncol 2011;6:1274-81.

31. Bae MK, Lee CY, Lee JG, et al. Predictors of recurrence after thymoma resection. Yonsei Med J 2013;54:875-82.

32. Fukui T, Fukumoto K, Okasaka T, et al. Prognostic impact of tumour size in completely resected thymic epithelial tumours. Eur J Cardiothorac Surg 2016;50:1068-74.

33. Okumura M, Miyoshi S, Takeuchi Y, et al. Results of surgical treatment of thymomas with special reference to the involved organs. J Thorac Cardiovasc Surg 1999;117:605-13.

34. Hayes SA, Huang J, Plodkowski AJ, et al. Preoperative computed tomography findings predict surgical resectability of thymoma. J Thorac Oncol 2014;9:1023-30.

35. Ma J, Sun X, Huang L, et al. Postoperative radiotherapy and tumor recurrence after complete resection of stage II/ III thymic tumor: a meta-analysis of cohort studies. Onco Targets Ther 2016;9:4517-26. 